\title{
Rescuing Basic Equality
}

\author{
Tom Parr and Adam Slavny
}

\begin{abstract}
In the debate on the basis of moral equality one conclusion achieves near consensus: that we must reject all accounts that ground equality in the possession of some psychological capacity (Psychological Capacity Accounts). This widely held view crystallises around three objections. The first is the Arbitrariness Objection, which holds that the threshold at which the possession of the relevant capacities places an individual within the required range is arbitrary. The second is the Variations Objection, which holds that there is rational pressure to acknowledge that variations in psychological capacities between individuals are morally relevant. The third is the No Rational Agency Objection, according to which Psychological Capacity Accounts have unpalatable implications for our treatment of humans who do not possess the relevant capacities. We develop a Psychological Capacity Account based on the capacity for a conception of the good and offer a novel defence of the account against these objections.
\end{abstract}

\section{Introduction}

People are morally equal. This claim is widely believed but notoriously difficult to clarify. It asserts some form of moral or political equality but does not describe the specific rights and duties that are equally held, or explain what grounds these equal distributions. This vagueness is problematic given that the belief that persons are equal is often regarded as central to our contemporary political and legal culture. Politicians appropriate the rhetoric of equality for strategic purposes, attesting to its caché with electorates, and the concept underpins some of the most important legal developments in the $20^{\text {th }}$ century, such as the emergence of an international human rights culture. It is also foundational to much normative philosophy, with many theories championing some set of rights or entitlements possessed equally by all citizens or all persons.

Philosophical debate has focused on articulating the property or set of properties that grounds the moral equality of persons. One suggestion is that human beings typically possess distinctive psychological capacities that explain both (i) why they are moral equals to each other, and (ii) why they are not morally equal to non-human animals, which lack such capacities. Let's call any such explanation of what grounds moral equality a Psychological Capacity Account. Two immediate problems arise for this family of views. The first is that human beings possess many psychological capacities, and so it is unclear which capacity or 
combination of capacities grounds moral equality. The second is that most capacities are possessed in different quantities by different individuals. How can a relation of moral equality be based on natural capacities that are distributed so unevenly? In other words, any Psychological Capacity Account must explain why equality is based on what John Rawls calls a range property. ${ }^{1}$ A range property is a binary property that one possesses in virtue of having a scalar capacity or set of scalar capacities that fall within a specified range. Only those who possess capacities within the required range, regardless of variations above or below this threshold, are moral equals. Although the underlying subvenient capacities are scalar, the range property itself is binary, since individuals possessing the relevant scalar capacities either will or will not fall within the specified range.

As with all philosophical debates, the literature on moral equality is riddled with disagreement. But surprisingly, there is one conclusion that has achieved near consensus: that Psychological Capacity Accounts are wrong. Indeed, Richard Arneson concludes that they are not even 'remotely credible'. ${ }^{2}$ This widely held view crystallises around three objections. The first is the Arbitrariness Objection, ${ }^{3}$ which holds that the threshold at which possession of the relevant scalar capacities places an individual within the required range is arbitrary. The second is the Variations Objection, ${ }^{4}$ which holds that there is rational pressure to acknowledge that variations in the subvenient scalar capacities are relevant. It is unclear why variations in individuals' capacities both above and below the threshold do not undermine the relation of moral equality. The third is the No Rational Agency Objection, ${ }^{5}$ according to which Psychological Capacity Accounts have unpalatable, even offensive, implications for our treatment of humans who do not possess the relevant capacities.

The objections target the entire family of Psychological Capacity Accounts on the assumption that they apply regardless of which capacities are thought to ground moral equality. We argue that this is a mistake; we cannot properly assess the objections without a specific view in mind. We aim to defend an account based on the familiar capacity to form, revise, and pursue a conception of the good. By defending this view, we hope to overturn the widespread belief that Psychological Capacity Accounts are a philosophical cul-de-sac.

\section{The Meaning of Basic Equality}

What does it mean to say that people are morally equal? The claim can be parsed in a number of ways: all persons are equally valuable from an impartial perspective; all persons possess the same set of rights; all persons are due equal treatment of some form, and so on. ${ }^{6}$ One way to cut through this ambiguity and focus on a specific set of issues is to consider cases in which the relation of moral equality is present. Consider the following set of cases: 
Medical Resources 1: We have resources to treat only one of two groups of patients, A and B. The groups are of equal size, their illnesses are equally life-threatening, and the treatments are equally effective. The only relevant difference between the two groups is that the patients in $\mathrm{A}$ are dogs and the patients in B are humans.

Medical Resources 2: Same as Medical Resources 1, except that groups A and $B$ both contain humans. Instead, the only relevant difference between the two groups is that the patients in A are 20 years old and the patients in B are 70 years old.

Medical Resources 3: Same as Medical Resources 2, except that groups A and $B$ contain humans of the same age. Instead, the only relevant difference is that the patients in A only just meet the threshold for possession of the relevant psychological capacities and the patients in $\mathrm{B}$ possess them to a much higher degree.

If it is impossible to increase the stock of medical resources, these cases require decisions about competing interests. In Medical Resources 1, we should treat the humans rather than the dogs. One explanation for this is that humans possess a set of psychological capacities that distinguish their claims on our resources from those of dogs. However, this does not imply that claims on resources by those who possess these capacities cannot vary. For example, in Medical Resources 2, we think that the age of the patients does affect their entitlement to medical assistance. Typically, it is much worse to die at 20 than at 70 , so the younger patients have a stronger claim. Perhaps others will reject this verdict and hold that there should be equal access even if the needs of both groups cannot be satisfied. We disagree, but our purpose here is not to settle this question but rather to explain how our claim about the scope of moral equality is circumscribed. Its proponents need not deny that there can be some morally relevant differences between moral equals.

We can illustrate our claim with Medical Resources 3. In this case, a specific type of variation between groups $\mathrm{A}$ and $\mathrm{B}$ - variation in the degree to which they possess the relevant capacities above a threshold - does not affect their claim to the resources. This is true even if those who possess the capacities to a greater degree benefit more from the same resources than those who possess them at the minimum threshold. ${ }^{7}$ We should therefore either divide resources equally between the groups or give each group an equal chance to access them. This is the judgement that an account of basic equality must defend.

These cases involve the interest in continuing to live. We make a similar claim about other interests, such as the interest in having opportunities to pursue one's conception of the good. Consider another set of cases: 
Paralysis 1: Two equally-sized groups of individuals, A and B, are unable to move. We have a drug that temporarily removes paralysis, but only enough to cure the patients for one day a week. The only relevant difference between the two groups is that members of $\mathrm{A}$ are dogs and members of $\mathrm{B}$ are humans.

Paralysis 2: Same as Paralysis 1, except that groups A and B both contain humans. Instead, the only relevant difference between the two groups is that the members of $\mathrm{A}$ are 20 years old and the members of $\mathrm{B}$ are 70 years old.

Paralysis 3: Same as Paralysis 2, except that groups A and B contain humans of the same age. Instead, the only relevant difference is that the members of A only just meet the threshold for possession of the relevant psychological capacities and the members of $B$ possess them to a much higher degree.

We make the same claims in this series of cases: in Paralysis 1, we should cure the humans once a week; in Paralysis 2, we should cure the young once a week; and, in Paralysis 3, we should not give preference to either group.

Psychological Capacity Accounts explain these judgments, but also go further. They show that the relevant capacities generate a distinctive set of basic interests that justify a corresponding set of rights and duties that are possessed equally by all individuals who have such interests. We will call the equal possession of these rights and duties basic equality, though we acknowledge that our use of this phrase may differ from others'. By caching out our view in terms of basic interests and a corresponding set of rights and duties, we hope to pre-empt the assumption that basic equality must be overly expansive in its implications. For example, one might take basic equality to mean that all people matter equally from a moral point of view or that there is some moral assessment of us that is always equal. These conceptions of basic equality, aside from being vague, are also too broad. ${ }^{8}$ After all, the claim that people are moral equals should not undermine the possibility that some of our rights can be forfeited or that we can assess some people as more virtuous than others. ${ }^{9}$

What is the content of the rights and duties that basic equality grounds? ${ }^{10}$ To answer this question, it may be helpful to refer to the distinction between substantive and formal equality. ${ }^{11}$ Substantive equality entails a non-instrumental commitment to equal claims to goods or resources of the kind that egalitarians typically endorse. ${ }^{12}$ This form of equality is controversial and it is rejected by theorists on both sides of the political spectrum, such as some prioritarians and sufficientarians (on the left) and some libertarians (on the right). ${ }^{13}$ We can contrast this with formal equality, according to which all members of a particular 
group equally possess some set of rights. This is a more limited requirement, since it is silent about the content of the rights that individuals possess equally. Unlike the former, this belief is shared by many views across the political spectrum. For example, both Nozickian libertarians and Rawlsian liberal egalitarians believe that persons share a set of rights, even though they disagree sharply about its content. ${ }^{14}$

It is not obvious that Psychological Capacity Accounts provide a general basis for either substantive or formal equality. They differ from substantive equality because the rights and duties of basic equality may fall short of a full set of egalitarian entitlements. We leave open the possibility that basic equality is consistent with some degree of socio-economic inequality, for example. ${ }^{15}$ It also differs from formal equality because there are some rights and duties - such as the right against suffering certain kinds of pain and the duty not to inflict it - that are not plausibly grounded in the same psychological capacities that ground basic equality. Whilst the equal possession of such rights and duties would be a kind of formal equality, it would not fall within the ambit of basic equality, since this has substantive commitments, namely to rights and duties whose content is shaped by the nature of the capacities in question. To put the point another way, basic equality does not entail substantive equality and is not entailed by formal equality.

We refrain from offering a more detailed exposition of the rights that basic equality grounds because there are a range of views available, and because it is not necessary to commit to any of them to investigate whether at least one Psychological Capacity Account can avoid the objections outlined above. Moreover, there are some rights plausibly connected to basic equality that are sufficiently complex to warrant a separate treatment. For example, the right to vote may be justified partly with reference to the psychological capacities that ground basic equality, but also because of its instrumental value. It is best to leave such cases out of our defence of basic equality.

Despite these caveats, it is worth emphasising how narrowing our project in this way does not define away some of the central criticisms levelled at explanations of basic equality. Our defence of basic equality must still overcome the Arbitrariness Objection, the Variations Objection, and the No Rational Agency Objection.

\section{Basic Interests and Basic Equality}

There are several psychological capacities that plausibly set most human beings apart, in degree or kind, from many non-human animals. Here we focus on a core capacity that defines humans as autonomous beings: the ability to form, revise, and pursue a conception of the good. ${ }^{16}$ Before we show how an account 
that incorporates this capacity into its explanation of basic equality avoids the objections, let's briefly outline what the capacity involves.

A conception of the good is a set of beliefs and attitudes about what our aims and ends ought to be. These conceptions manifest in a multitude of decisions and behaviours: our career paths, how we spend our leisure time, the associations to which we belong, and so on. They can encompass metaphysical beliefs, since such beliefs often have implications about how we ought to live. For example, Christians who believe in the divinity of Jesus Christ may take this as a reason to follow his teaching. The core beliefs that constitute a person's conception of the good are about values, such as the belief that it is good to live a life of generosity, bravery, patriotism, or spirituality. Taken together, and over the course of a lifetime, these beliefs form an overall vision of what it is to live well.

To pre-empt the common criticism that this analysis is unduly individualistic or rationalistic, we offer some clarifications. First, an individual may conceive of her good as relative to her own life or as something that would be good for anyone. She may believe that a spiritual life is just one of many ways to flourish or that others can flourish only if they live such a life - both attitudes would be constitutive of her conception of the good. Second, her conception of the good may aim at either personal or impersonal value, and it may be either self- or other-regarding. She may think that she ought to dedicate her life to achieving impersonal value, such as the protection of endangered species, or by furthering the interests of others, so her beliefs about the good need not strictly relate to her personal good. Finally, her conception of the good need not be fully precise, systematic, or consistent. ${ }^{17}$ No one lives their life as if they are building a house: in a stage by stage execution of a pre-conceived plan. Our conceptions of the good are constantly evolving, contain many inconsistencies, and are often unfulfilled due to weakness of will or external impediments.

Here is a rough statement of the relevant capacity:

The Capacity for a Conception of the Good (CCG): An individual has the capacity for a conception of the good if and only if she can form, revise, and pursue beliefs about the good on the basis of critical deliberation.

According to this definition, an individual must be able to form beliefs about the good, which encompass both beliefs about what one's good is and how one can pursue it. However, these beliefs need not track objective reasons. Though we do not here commit to an attitude-independent account of human flourishing, if such an account is correct, it is possible for a person to have a wrongheaded conception of the good whilst still possessing the relevant capacity. 
It is also important that individuals form beliefs about the good at least partly on the basis of critical deliberation. However, individuals can vary significantly, and the threshold of critical deliberation is relatively undemanding. Consider two individuals, Ali and Terry. Ali carefully considers multiple options in determining her good. She seeks out information about a diverse range of mutually exclusive conceptions and extensively compares them. She also reflects on the value of these various options and the way they might contribute to her good. She makes her choices for the reasons she identifies through this critical process. Her resulting conception of the good is comprehensive and consistent in the sense that it influences a wide range of her beliefs and choices and it does not contain any contradictions. She frequently reflects on her choices and occasionally revises them in the light of this. Finally, she has a high degree of selfawareness about the deliberative process in which she engages. Terry differs from Ali in all these respects. Although he meets a minimum standard of critical deliberation, because of his limited capacities he rarely considers his options or their value and he has a deeply fragmented and inconsistent set of beliefs about his good. He is also so impulsive that his beliefs about the good often fail to guide his action. Although Ali represents the ideal deliberator, Terry still meets the required threshold. He just about possesses a capacity to pursue a conception of the good, albeit a rough, impulsive, and inconsistent one.

As our comparison between Ali and Terry shows, individuals can vary significantly in how well they exercise their CCG. Some can employ this ability more consistently, critically, and reflectively than others. This reveals a distinction between two kinds of interests. The first is the interest in exercising a capacity well. It is plausible that we have an interest in achieving excellence in exercising some of our physical and psychological capacities. Indeed, many dedicate their lives to such achievements. It is also plausible that the strength of this interest is roughly scalar. The better our achievement, the better we satisfy our interest in exercising our capacities well. But we can contrast this with a second, distinct interest in exercising a capacity tout court. Our interest in the mere exercise of a capacity does not vary according to how well we exercise it, as exercising a capacity poorly entails exercising it tout court just as must as exercising it well. In the context of the CCG, this distinction explains the sense in which we have an interest in participating in the central human practice of forming, revising, and pursuing a conception of the good, which is independent of our interest in exercising this capacity well. The capacity to pursue a conception of the good tout court is a range property. There is a threshold below which an individual lacks the necessary subvenient properties for the CCG. But variations in those subvenient properties above this threshold do not affect the ability to exercise it tout court, even though they do affect the ability to exercise it well. 
It is a mistake to conclude that, merely because it is a range property, the interest in exercising the CCG tout court can ground basic equality. Rather, it's being a range property is necessary but not sufficient for this purpose. We also need a substantive moral argument in support of this claim. However, it's not difficult to see how the interest in exercising the CCG tout court can play this role, given its intimate connection to the familiar idea that individuals have a weighty interest in being the author of their own lives. Different philosophers take this to entail different things. For some, an individual enjoys self-authorship whenever she is not wrongfully coerced. For others, self-authorship is much more demanding. Perhaps it requires that she have an adequate range of options from which to choose, and also that others refrain from shaping her ethical values or the character of the options that are available to her. What unites these views is their convergence on the idea that every individual has an important interest in determining the goals that she pursues.

We will not develop a specific account of our interest in self-authorship here. Rather, we suggest that all of these views require something like the CCG, but not necessarily the ability to exercise it to a high standard. Being the author of one's own life, on most plausible conceptions, is an interest in exercising a capacity tout court, rather than exercising it well. That is, it is an interest in participating in the practice of self-authorship. Self-authorship means living a life according to one's own values, not necessarily the most rationally justifiable, consistent, and reflective values. We do not deny that there is an additional interest in exercising the CCG well, just as there is an interest in achieving excellence in the exercise of many other capacities. For example, suppose that Ali pursues her ambition to become a writer and political activist, achieving widespread admiration, whilst Terry dedicates his time to watching every available soap opera. We might think that Ali exercises her capacities better than Terry. But, as long as Terry meets the relevant threshold, we should not deny that he exercises his CCG, and therefore lives a self-authored life.

\section{The Arbitrariness Objection}

Let's revisit the first objection to Psychological Capacity Accounts. This is the worry that the threshold at which the possession of the relevant scalar properties places an individual within the range that grants her basic equality is arbitrary. Since the subvenient properties that comprise the CCG are scalar, there is no obvious point to place the threshold. If individuals can possess rational agency in greater or lesser quantities, why is the threshold placed just where defenders of the account say it is? Without a convincing answer, we might suspect that the threshold is so placed simply to meet pre-established conclusions, such as the almost universal belief that most human beings fall above the threshold whilst non-human animals fall below it. Not only is such an argument circular, since it assumes a particular 
placement for the threshold in order to 'show' that human beings lie above it, it also smacks of speciesism.

The Arbitrariness Objection is the weakest of the three objections. The simple answer to it is that the possession of the CCG determines where the threshold lies. The objection is too quick to assume that the range property must be arbitrary simply because it attaches to a set of properties that, taken individually, are scalar. The source of the confusion, we suggest, is a failure to appreciate the difference between the complex capacities represented by the CCG and the subvenient properties that constitute them. Though the underlying properties are scalar, possession of the CCG is not. The question about whether an individual possesses the CCG must, in most cases, be met with one of two answers. On the account that we defend, therefore, we have principled reasons for placing the threshold at a particular level as that is the level at which possession of the CCG emerges from the subvenient capacities.

This is not to deny that the threshold is subject to vagueness. Specifically, there may be two forms of vagueness. First, the threshold may be indeterminate: there may be no precise increment at which possession of some scalar property establishes the CCG. Additionally, there may be no unique set of underlying capacities that underpin the CCG, but multiple sufficient sets. Second, the threshold may be subject to epistemic vagueness, such that it is difficult or impossible to ascertain whether borderline cases fall above or below the threshold.

Do these admissions of vagueness threaten the previous claim that possession of the CCG is binary? We think not. This is because binariness is not itself a binary property. Binariness exists on a spectrum, with fully scalar properties at one end and fully binary properties at the other. The kind of binariness that our argument requires is not absolute. It can tolerate a sizable number of cases that cannot be said either to possess or not possess the property. Such cases are indeterminate, but they do not threaten the discreteness of the two categories in question. This is distinct from the idea that there are continuous gradations between the two categories. Our view permits indeterminate cases, but not cases that can be placed on specific gradations between possessing and not possessing the CCG.

Strictly speaking, only a threshold based on the possession of fully scalar properties would be arbitrary. But as long as there are some cases falling above and below the threshold, we can identify some criteria for determining where it is located. If this were true of the possession of the CCG, the view would be unsatisfactory for other reasons, as it would be overwhelmed with indeterminacy. But this is not the case. When compared with the full range of the scalar properties that underpin the CCG, the area of indeterminacy is relatively small. 
To return to the Arbitrariness Objection, conceding that the threshold is vague in one or more of these senses is not to concede that it is arbitrary. We retain criteria by which to judge where the threshold lies, even if their application is sometimes indeterminate and/or difficult. Of course, vagueness has its own problems, particularly when we face borderline cases. But this is a much less significant problem than arbitrariness. Whereas arbitrariness is a fatal shortcoming, since it suggests a lack of justification, vagueness is problematic for only borderline cases.

\section{The Variations Objection}

The second objection is that there is rational pressure to acknowledge that the scalar properties on which the range property depends are also relevant. It will be helpful to distinguish two versions of this objection. One focuses on variations above the threshold and the other on variations below it. It is unclear why variations in individuals' CCG both above and below the threshold do not undermine the relation of basic equality. Although we have clarified that the possession of the CCG is a binary property (albeit one that is subject to vagueness), our ability to exercise this capacity well is scalar and varies significantly. Recall the contrast between Ali, who is able to exercise her CCG exceptionally, and Terry, who barely possesses it at all. Though they equally share the property of possessing the capacity, they are not equal in terms of how effectively they can exercise it. Similarly, compare Ali* with Terry*. Ali* falls just short of the threshold, whilst Terry* is well below it. Why shouldn't these differences below the threshold affect their moral entitlements? The Variations Objection challenges us to explain why these differences do not threaten basic equality.

To help evaluate this objection, consider the following example:

Prison Chess: A prison has the resources to allow its inmates to participate in only one creative and intellectual activity: chess. Some inmates are just about competent to play the game whilst others are excellent. The prison manager has the task of allocating limited playing time amongst inmates.

Before we discuss how this case helps us respond to the Variations Objection, it will be useful to clarify the importance of this example for basic equality. Here are three respects in which Prison Chess helps to illuminate basic interests. First, the interests in both cases are non-exhaustive, in the sense that they exist alongside other interests. Just as inmates have interests aside from playing chess, so too individuals have interests aside from those generated by the CCG. Moreover, engaging with the game may satisfy multiple interests, including the interest in having a pleasurable experience. We focus on the specific interest in participating in the creative and intellectual experience of playing chess. Second, although they are non-exhaustive, the interests in both cases are part of a set of the most 
significant interests that an individual has. Notwithstanding the differences between various theories of human flourishing, both creative and intellectual expression and autonomous living feature heavily in most. Third, the interests are distinctive and are connected with a set of opportunities that are uniquely capable of realising them. In other words, these interests are ones that cannot be realised through any alternative means (in Prison Chess, this is because we stipulate that the inmates lack access to any other form of creative or intellectual stimulation). Taken together, these three features are capable of justifying certain rights and, in particular, the rights that we can justify by appeal to a concern for basic equality..$^{18}$

Let's return to Prison Chess. Should the prison manager allocate playing time according to chess ability or apportion it equally? All else being equal, it is intuitive that the manager should allocate playing time equally, irrespective of variations in talent above the threshold. A barely competent player is entitled to the same amount of time as an excellent player. This means that resources should be allocated to inmates on the basis of a range property: those who fall within the range are entitled to certain goods and variations within the range do not affect the size of the entitlement. We can contrast this with how we ought to allocate resources in a professional chess team. Since the overarching aim in the professional team is to foster excellence, it is appropriate to allocate resources in a way that is sensitive to variations in ability. But given the unique creative and intellectual role that chess plays in the inmates' lives, and given the limitation on the prison's resources, it would be objectionable for the manager to aim at fostering excellence. In other words, she ought to give considerable priority to the interest in exercising creative and intellectual capacities over the interest in attaining excellence.

One might object that the prison authorities have professional duties to prisoners, and it is these duties that explain how the officers should distribute resources in this case. We doubt that our judgement about Prison Chess is dependent on this contextual factor. We discuss the distribution of resources in prison because it is an intuitive example, but that same analysis applies in other cases of this kind. For example, a group stranded on a desert island with only a chess board should distribute resources similarly. Additionally, referring to professional duties is not dispositive because the equal distribution of resources required by those duties may depend on the interest-based argument we provide. After all, the professional duty may require treating the prisoners fairly and equally, where this is true partly for reasons relating to their basic equality.

The same kind of reasoning shows how we can respond to the Variations Objection. We have explained why the interest in exercising the CCG tout court is both weighty and distinct. In these respects, it is analogous to the inmates' 
interest in playing chess. Accordingly, we ought similarly to give considerable priority to this basic interest over the interest of a few individuals in exercising their CCG to a much higher degree. The Variations Objection fails because it confuses the interests on which basic equality depends. Entitlements grounded in basic equality do not depend directly on interests that track scalar psychological properties. They depend on the distinct interest in exercising the CCG tout court, in participating in living a self-authored life rather than doing so to a high standard. Moreover, since this interest plausibly has considerable priority over the interest that does track scalar properties (the interest in exercising the capacity well), we have an explanation of why variations above the threshold do not affect the entitlements.

We can now see why, in Medical Resources 3 and Paralysis 3, variations in the degree to which A and B possess the CCG do not affect their entitlements either to medical resources or to freedom of movement. In Paralysis 3, the interest in pursuing one's conception of the good for a limited time has priority in the allocation of resources. Similarly, in Medical Resources 3, since access to lifepreserving treatment is a precondition for the exercise of the CCG, equally protecting opportunities to exercise it tout court takes priority over giving greater protection to those who can exercise it well. For example, let's suppose that one patient has sufficient resources to exercise their CCG tout court but that they require a further unit to enable them to exercise it better. Let's also suppose that another patient requires a further unit to exercise their CCG tout court. In conflicts of this kind, when resources are scarce, the interest in exercising the CCG tout court has priority over the interest in exercising it well.

We conceded earlier that exercising the CCG well is a morally relevant interest. One might then object that the combined interests justify unequal distribution of rights. Why can't we say that those who are just about competent and those who are excellent in the exercise of their CCG have an equal interest in exercising the capacity tout court, but since only the latter also have an interest in attaining excellence, they have a claim to favourable treatment based on the combined weight of these interests? In circumstances of overabundance, when each individual has fully satisfied their interest in exercising their CCG tout court, perhaps some individuals would have a claim to extra resources for this reason. We claim only that the interest in exercising the CCG tout court has priority in the event of a conflict. Furthermore, most cases in which basic equality is pertinent do not involve an overabundance of resources: in the world in which we live, we cannot full satisfy everyone's interest in exercising their CCG tout court. Consequently, appealing to one person's interest in exercising the CCG well cannot justify the use of a resource that could otherwise be used to satisfy another person's interest in exercising it tout court. For example, in Prison Chess, the allocation of more time to skilled players deprives others of the ability to 
participate, or at least reduces time in which they can satisfy their interest in merely participating.

A different objection is that our reasoning justifies only the weighted priority of the interest in exercising the CCG tout court, rather than absolute priority. Perhaps there are beings capable of such sublime autonomy that their achievement can justifiably deprive others of the chance to take part. This would be analogous to a version of Prison Chess in which one inmate enjoys almost super-human abilities but needs a greater-than-equal share of playing time in order to realise her talent. We stress that there is no need for us to exclude this theoretical possibility. Our claim is the more practically relevant one that no human deliberators in fact meet this condition.

For distinct reasons, variations below the threshold also do not threaten our defence of basic equality. In Prison Chess, a person who just about lacks the capacity to play chess is similar to a person who is nowhere near it in the sense that both lack the capacity to participate in an activity in which they would otherwise have a weighty interest. But this similarity can mask other important differences, and we should point out one respect in which Prison Chess is disanalogous to Paralysis and Medical Resources.

If the prison manager were to allocate a chessboard to a person who is unable to play chess (assuming she does not use it for any other valuable purpose), it is a wasted resource. By contrast, in Paralysis and Medical Resources, freedom and health are valuable even to those who lack a CCG. For example, non-human animals would benefit from these things even if the interests thereby satisfied are different to the human interest that would be satisfied by the same resources. Therefore, we accept that variations below the threshold might matter in this way, whilst variations above it do not. In this respect, the view we defend is asymmetrical. This asymmetry arises from the fact that there may be important interests that depend on underlying capacities below the threshold for the CCG but not above it.

The more modest point is simply that, as we emphasised in section 3 , the activities that are made possible by an individual's possession of the CCG tout court have central and distinctive value, even if there are other valuable activities that do not depend upon an individual's possession of it. It is important to emphasise that this point does not concede too much. As we noted before, the threshold may be subject to significant vagueness. Individuals who possess the subvenient capacities to a large degree but fall short of the CCG will be very difficult to identify. Our intuitions about the entitlements of such individuals will be heavily affected by this vagueness. Moreover, we may have good reasons to err on the side of caution and treat individuals as if they possess the CCG unless we are reasonably certain that they do not. All of this is important for how we 
address borderline cases, but it also underscores the point that there is a substantial difference between those who possess the CCG and those who clearly do not. Whilst those who clearly fall below the threshold, such as dogs, have some interest in accessing resources based on exercising the same subvenient capacities that generate the CCG at higher levels, this interest does not approach the interest in exercising the CCG.

Nevertheless, some have pressed the Variations Objection to basic equality on the grounds that variations in psychological capacities below the threshold seem to make a moral difference. ${ }^{19}$ For example, many people believe that it would be wrong to perform the kind of experimentation on a chimpanzee that it might be permissible to perform on a mouse. We can explicate this difference in terms of the more developed psychological capacities of the chimpanzee. Why, then, should variations above the threshold not make a moral difference when variations below the threshold do? The answer is that there are complex capacities and corresponding interests (besides the CCG) that occur below the threshold of basic equality. One of these is the ability to experience emotional distress, which is possessed by some living things and not others. Those with this capacity are due moral treatment that those without it are not. This is one capacity that may distinguish the mouse from the chimpanzee and thus explain why certain kinds of experimentation, which tend to cause emotional distress in some animals, cannot permissibly be performed on chimpanzees. We leave open the possibility that there are other morally relevant complex capacities, with corresponding interests, that occur above the threshold. We are unsure what these may be, but if they exist they do not negate the point that the rights and duties grounded in the possession of the CCG should be equally distributed.

\section{The No Rational Agency Objection}

The third objection to Psychological Capacity Accounts is that they have unpalatable, perhaps offensive, implications for our treatment of those humans who do not possess the CCG, such as children or adults with severe cognitive disabilities. This is the No Rational Agency Objection. We must be careful here to clarify the implications of our view. It bears noting that that the threshold for possession of the relevant interest is reasonably low. As we explained in section 3, since the interest to which we appeal is in pursuing a conception of one's good tout court, rather than doing it well (or indeed without assistance), a person need not be in possession of typical levels of intelligence or agency to enjoy this interest. One virtue of our view is that it explains how children and those with a wide range of cognitive impairments often have the same interest as others in exercising their CCG. 
Nevertheless, those who do not possess the CCG are not entitled to basic equality, and this implication may be rejected by some. To illustrate, consider the following case:

Medical Resources 4: We have resources to treat only one of two groups of patients, A and B. The groups are of equal size, their illnesses are equally life-threatening, and the treatments are equally effective. The only relevant difference between the two groups is that the patients in A have such severe cognitive disabilities that they are completely unable to reason or make choices about their good for themselves.

It is not clear which, if any, humans meet this description. But assuming there are humans who completely lack the CCG (group A), does our view imply that group B, and not group A, are entitled to the treatment? Although it appears to have this implication, this would be too hasty. Our view implies only that a concern for possession of the CCG will not yield the conclusion that the two groups have equal claims to the treatment. On reflection, this is obvious. It follows from the fact that members of group A lack the CCG. It is true that, on our view, the possession of the CCG grounds the equal possession of a set of rights, and individuals who lack it do not possess these rights. But this is not an offensive implication: individuals do not have rights when those rights are grounded in interests that they lack. It is acceptable that a young infant lacks some of the rights, such as the right to vote, enjoyed by adults who possess the relevant capacities that give her an interest in voting.

Moreover, young infants may enjoy a number of rights based on the interests that they do have. Similarly, adult humans who lack the CCG may also possess an array of rights grounded in their other interests. Consequently, those who do not possess the CCG may enjoy the same rights but on different grounds. At this point, it might be objected that the same can be said about our initial judgments in Medical Resources 1 and Paralysis 1. Unequal possession of the CCG does not yield the conclusion that dogs and human beings should be treated unequally. It is consistent with our view that dogs and humans should be treated equally on the basis of some other consideration.

Whilst this is true, whether equal treatment is justified in any given scenario depends on whether there is a plausible substantive argument showing that there are independent considerations that justify this treatment. We doubt there are any considerations in Medical Resources 1 and Paralysis 1 that justify equal treatment of dogs and humans, but it is more plausible that such alternative considerations exist in Medical Resources 4. For example, it could be argued that membership of the human species yields separate reasons to treat human beings equally, even if they do not all possess the CCG. On this view, respect for the value of human life is not grounded solely in the capacities of individuals, but the typical life-cycle to 
which the individual belongs. ${ }^{20}$ An alternative view is offered by Eva Kittay, who rejects the focus on psychological capacities altogether, and instead emphasises the value of the relationships we establish with other members of the human community, regardless of their psychological capacities. The significance of these relationships is incomparable to any relationship a human can have with a nonhuman animal (indeed, Kittay thinks the very comparison is offensive) and those who participate in these relationships are entitled to the support and resources required to fulfil the obligations that they generate. ${ }^{21}$

These views face serious challenges. Why should the typical life-cycle of a species have any relevance to our treatment of a particular individual who does not have such a life-cycle? Similarly, although it is plausible that our relationships with members of the human community are significant, the appeal to the relationship rather than the intrinsic worth of any individuals is problematic, as what does it imply about our treatment of severely cognitively impaired human beings who do not have such relationships? We do not have the space here to embark on detailed critical analysis of these and other views. Instead, we note only that our view is consistent with these attempts. ${ }^{22}$ Defending basic interests arising from the CCG does not preclude the possibility that other factors are also relevant and explain our intuitions about some contested cases.

In sum, we believe there are two possible responses to Medical Resources 4. One is the controversial judgment that we should give priority to group $\mathrm{B}$ on the grounds that only they possess the CCG. A second possibility is that there is some other consideration that explains why both groups have equal claims in this case. Unless it can be shown that the rights grounded in the CCG somehow undermine other candidate justifications for equal treatment, we must be open to the possibility that there are multiple grounds that justify distinct but overlapping sets of rights.

In the light of our claim that our account is consistent with some other attempts to demonstrate basic equality, one might worry that our argument is redundant since, if there is some other argument that can justify equal claims to treatment between those who possess the CCG and those who lack it, then it's now unclear what turns on its possession. This claim is also too strong. We should emphasise that, whilst the possession of the CCG is not necessary to ground an equal set of rights, it is sufficient to do so. ${ }^{23}$ The plausibility of the view must also be considered in the context of its ability to respond to the Arbitrariness Objection and the Variations Objection, where we argue that our view has an edge on its competitors.

There is a further worry that, even if those who do not possess the CCG may have interests that overlap with those who do, this does not entail equal treatment. It may be argued that the possession of the CCG confers general value 
or moral status upon its holders. Accordingly, when two beings with different properties have the same interest, we can decide which should have priority by determining which being has greater value or moral status. For example, a dog and a person may have the same basic interest in continuing to live, but since the latter is grounded in a more valuable capacity than the former, then we have a substantive reason to give priority to the person over the dog. This seems to provide us with a justification for the judgment in Medical Resources 1. On the other hand, if this is true, we cannot conclude that two beings with different properties have equal claims. Hence, it becomes more difficult to see why groups $\mathrm{A}$ and B should have equal claims to medical treatment in Medical Resources 4 in so far as we assume that members of the two groups have the same interest grounded in different capacities. The possession of the CCG may make a being's interest more significant than the same interest possessed by a being that lacks the CCG.

Admittedly, it is intuitive that a person's interest in continuing to live has priority over that of a dog. But it does not follow that this is because the CCG confers general value or status. We can draw this conclusion only if the interests in question are substantively similar, for only then can we safely attribute the stronger claim of one party to a general value or status-conferring property rather than a substantively different interest. For example, the interest in continuing to live, although it is possessed by both humans and dogs, is substantively different for each group, since death frustrates a person's autonomously chosen plans and projects, but not those of dogs. Even the interest in avoiding physical pain may be different if it is accompanied by distinct forms of anxiety and emotional distress in humans but not dogs. Ultimately, as a result of interaction effects between different properties, it is very difficult to construct a case in which the two interests are substantively similar. However, without such cases, it is difficult to motivate the view that the CCG confers general value or status.

A final observation about the No Rational Agency Objection is worth making. The objection encourage us to think more carefully about which ground we should we honour with the title of basic equality. Part of the problem here is the language in which these debates are traditionally couched. Basic equality in popular rhetoric has great import and any denial of it is perceived by some to legitimate serious wrongdoing and inhumane treatment to the excluded group. One thing philosophy can do to address this is to demystify basic equality. When basic equality is understood as the equal distribution of rights based on a particular interest, it becomes clear that there are many relations of equality, distinct from what we have called basic equality, each obtaining between different but overlapping groups of individuals, depending on who possesses the relevant interest. 
One strategy would be to abandon the term 'basic equality', since it seems to imply that beings outside the favoured group are due less moral concern than those within it. This implication is fallacious for the reasons we gave, but the fallacy might justify altering the language used in order to avoid misunderstanding. In fact, the language of basic equality arguably courts this interpretation. Perhaps, for these reasons, we are wrong to employ this language without alteration. However, there are reasons to retain the terminology as well. As we have argued, Psychological Capacity Accounts can explain a range of judgments and convictions that are commonly associated with a foundational form of equality. It may be better, then, to keep the term but explain how its alleged offensive implications are false. This is the strategy we adopt in the present paper, and we hope we have explained why basic equality, as we understand it, is only one moral consideration among others, albeit a significant one. $^{24}$

\section{Tom Parr, Department of Government, University of Essex}

\section{Adam Slavny, School of Law, University of Warwick}

\footnotetext{
${ }^{1}$ Rawls, 1999, pp. 441-2. See also Carter, 2011.

${ }^{2}$ Arneson, 2015, p. 36.

${ }^{3}$ Arneson, 2015, pp. 36-7.

${ }^{4}$ Arneson, 2015, pp. 36-7; Carter, 2011, pp. 549-50; Husi, 2017; and Sher, 2015, p. 19.

${ }^{5}$ McMahan, 2008.

${ }^{6}$ For the most part, we put aside a related but separate claim regarding the equal wrongness of killing. For discussion of this topic, see McMahan, 2002, pp. 233-48.

${ }^{7} \mathrm{We}$ do not commit to this claim. To see why, consider a case in which four humans and a dog will drown on a sinking lifeboat, unless either one human or the dog is thrown overboard. Tom Regan famously claims that, despite the dog's equal moral standing to the humans, it is justifiable to abandon the dog on the grounds that it would suffer less harm than any of the humans would suffer. In turn, Regan thinks this is because the dog has fewer opportunities for a valuable life. See Regan, 1983, p. 324. Taking a cue from Regan, one could argue that members of groups A and B have the same status, but group B benefit more from their greater psychological capacities. Thus, we have a reason to prioritise the claims of members of group B to medical assistance. We resist this claim on the grounds that, above a threshold, possessing the psychological capacities at a higher level carries risks as well as opportunities. For example, compare a mistake made by a professional physicist with a mistake made by a student. Arguably, the physicist's mistake is worse for her because she has greater ability: the greater the mind, the greater the potential for waste. It must not be assumed without further argument that possessing the capacities at a higher level makes one better off.

${ }^{8}$ See also Kirby, 2018, p. 314.

${ }^{9}$ For the criticism that differential assessment of moral virtue might threaten basic equality, see Cupit, 2000, pp. 114-15. For the criticism that differential treatment of the guilty and the innocent might threaten basic equality, see Steinhoff, 2015.

${ }^{10} \mathrm{We}$ omit discussion of the site of justice. For example, we do not argue that duties of basic equality apply to states rather than individuals. For further discussion, see Carter, 2013.
} 
${ }^{11}$ Similar distinctions are drawn by other commentators. See Lippert-Rasmussen, 2015, ch. 2; Rawls, 1999, pp. 441-2; and Raz, 1978.

${ }^{12}$ Egalitarians disagree about the goods or resources to which people have an equal claim. Some distributive egalitarians focus on resources, whilst social egalitarians emphasise equal respect. See Dworkin, 2000; and Anderson, 1999.

${ }^{13}$ Nozick, 1974. See also Parfit, 1997; and Frankfurt, 1987.

${ }^{14}$ Nozick, 1974, pp. 49-51; and Rawls, 1999, pp. 441-9.

${ }^{15}$ In Rawls's theory of justice, basic equality is consistent with socio-economic inequality for at least two reasons. First, possession of the two moral powers is not sufficient to ground principles of distributive justice, since those who possess the two moral powers must also satisfy other criteria, such as participating in a scheme of social cooperation. Second, the two moral powers ground principles of distributive justice, such as the difference principle, that themselves permit some socio-economic inequality.

${ }^{16}$ This is one of the two moral powers that form the basis of Rawls's account of basic equality. We do not adopt Rawls's theory in full here, as we argue that the capacity to form, revise, and pursue a conception of the good by itself allows us to avoid the objections.

${ }^{17}$ For further discussion see Rawls, 1996; and Quong, 2011, pp. 13-14.

${ }^{18}$ In this respect, we can situate our account of basic equality within an interest theory of rights. For discussion of the interest theory of rights, see Raz, 1986, ch. 7.

${ }^{19}$ For a forceful version of this objection, see McMahan, 2008, p. 83.

${ }^{20}$ For a defence of this view, see Kumar, 2008, p. 76. For a defence of the idea that species membership is methodologically important for assessing the value of lives, see Zuolo, 2016.

${ }^{21}$ See Kittay, 2010, pp. 409-12.

${ }^{22}$ For a more detailed analysis of whether species membership may make a moral difference, see McMahan, 2002, ch. 3.

${ }^{23}$ Thus, we agree with Rawls who writes, 'We see, then, that the capacity for moral personality is a sufficient condition for being entitled to equal justice'. See Rawls, 1999, p. 442. In a similar vein, Federico Zuolo writes, 'the normative considerations included in the attribution of moral status are in a sense only pro tanto considerations, although they are fundamental. The fact of being both pro tanto and fundamental is not a contradiction because they are fundamental in that they concern the basic features of a being which give us only initial normative guidance about what we owe to that being'. See Zuolo, 2017, p. 181. See also Husi, 2017, p. 382, where he writes, 'The denial of moral status equality does not justify let alone call for discrimination, exclusion or oppression. It undercuts one justificatory avenue to egalitarian principles leaving others untouched'.

${ }^{24}$ For helpful comments and discussion, we thank three anonymous reviewers for this journal, Richard Arneson, David Axelpie, Paul Bou-Habib, Clare Burgum, James Christensen, Matthew Clayton, Jeff Howard, Hwa Young Kim, Zoltan Miklosi, Bill O’Brian, Tom Rowe, Asbjørn Aagaard Schmidt, Areti Theofilopoulou, and Andrew Williams, as well as audiences at UCL's Legal and Political Theory seminar series and the University of Warwick's Centre for Ethics, Law, and Public Affairs.

\section{References}

Anderson, E. (1999) 'What's the Point of Equality?', Ethics, 109, 287-337.

Arneson, R. (2015) 'Basic Equality: Neither Acceptable nor Rejectable', in U. Steinhoff (ed.), Do All Persons Have Equal Moral Worth? On "Basic Equality" and Equal Concern and Respect (Oxford: Oxford University Press), 30-52. 
Carter, I. (2011) 'Respect and the Basis of Equality', Ethics, 121, 538-71.

Carter, I. (2013) 'Basic Equality and the Site of Egalitarian Justice', Economics and Philosophy, 29, 21-41.

Cupit, G. (2000) 'The Basis of Equality', Philosophy, 75, 105-25.

Dworkin, R. (2000) Sovereign Virtue: The Theory and Practice of Equality (Cambridge, MA: Harvard University Press).

Frankfurt, H. (1987) 'Equality as a Moral Ideal', Ethics, 98, 21-43.

Husi, S. (2017) 'Why We (Almost Certainly) are Not Moral Equals', Journal of Ethics, 21, 375-401.

Kittay, E. F. (2010) 'The Personal is Philosophical is Political: A Philosopher and Mother of a Cognitively Disabled Person Sends Notes from the Battlefield' in E. F. Kittay and L. Carlson (eds), Cognitive Disability and Its Challenge to Moral Philosophy (Oxford: Blackwell), 393-413.

Kumar, R. (2008) 'Permissible Killing and the Irrelevance of Being Human', Journal of Ethics, 12), 57-80.

Lippert-Rasmussen, K. (2015) Luck Egalitarianism (London: Bloomsbury).

McMahan, J. (2002) The Ethics of Killing: Problems at the Margins of Life (Oxford: Oxford University Press).

McMahan, J. (2008) 'Challenges to Human Equality', Journal of Ethics, 12, 81104.

Nozick, R. (1974) Anarchy, State, and Utopia (New York: Basic Books).

Parfit, D. (1997) 'Equality and Priority', Ratio, 10, 202-21.

Quong, J. (2011) Liberalism Without Perfection (Oxford: Oxford University Press).

Rawls, J. (1996) Political Liberalism (Columbia: Columbia University Press).

Rawls, J. (1999) A Theory of Justice: Revised Edition (Cambridge, MA.: Harvard University Press).

Raz, J. (1978) 'Principles of Equality', Mind, 87, 321-42.

Raz, J. (1986) The Morality of Freedom (Oxford: Clarendon Press).

Sher, G. (2015) 'Why We Are Moral Equals', in U. Steinhoff (ed.), Do All Persons Have Equal Moral Worth? On "Basic Equality" and Equal Concern and Respect (Oxford: Oxford University Press), 17-29. 
Steinhoff, U. (2015) 'Against Equal Respect and Concern, Equal Rights, and Egalitarian Impartiality' in U. Steinhoff (ed.), Do All Persons Have Equal Moral Worth? On "Basic Equality" and Equal Concern and Respect (Oxford: Oxford University Press).

Zuolo, F. (2016) 'Individuals, Species and Equality: A Critique of McMahan's Intrinsic Potential Account', Journal of Value Inquiry, 50, 573-92.

Zuolo, F. (2017) 'Equality, its Basis, and Moral Status. Challenging the Principle of Equal Consideration of Interests', International Journal of Philosophical Studies, $25,170-88$. 